\title{
Clinico-epidemiological Profile of Obsessive Compulsive Patients in a Tertiary Care Hospital in Mangalore, India: A Retrospective Study
}

\author{
Nitin Joseph ${ }^{1, *}$, Prima Cheryl D'Souza ${ }^{2}$, Apurav Singh ${ }^{3}$, Tobin P Joseph ${ }^{3}$, Rahul Kondaveti ${ }^{3}$, \\ Mancy Mothsera ${ }^{3}$, Fathima Noureen Kilikkot ${ }^{3}$

\begin{abstract}
${ }^{1}$ Department of Community Medicine, Kasturba Medical College, Mangalore, Manipal Academy of Higher Education, Manipal, India ${ }^{2}$ Department of Psychiatry, Kasturba Medical College Hospital, Attavar, Mangalore, Manipal Academy of Higher Education, Manipal, India

${ }^{3}$ Kasturba Medical College, Mangalore, Manipal Academy of Higher Education, Manipal, India

*Corresponding Author: drnitinjoseph@gmail.com
\end{abstract}

Received October 17, 2019; Revised November 30, 2019; Accepted December 4, 2019

Copyright $C 2019$ by authors, all rights reserved. Authors agree that this article remains permanently open access under the terms of the Creative Commons Attribution License 4.0 International License

\begin{abstract}
Introduction: Obsessive-compulsive disorder (OCD) is the fourth most common mental illness. It is associated with a wide range of functional impairments and therefore adversely affects the quality of life of patients. Objectives: To assess the risk factors, clinical features and management practices of OCD based on findings were stated in medical records. Methodology: The secondary data from the medical records of 9 OCD patients admitted in a tertiary care hospital over the past 10 years were recorded in a semi-structured proforma. Severity of OCD was assessed using Yale Brown Obsessive Compulsive Scale scores. Results: Mean age of onset among all patients $(n=9)$ was $27.9 \pm 15.2$ years. Family history of OCD was reported among $3(33.3 \%)$ patients. Six had predominant obsessions while the rest 3 had mixed type. The most common type of obsession was of sexual type reported among 3 patients. The most common compulsion reported was the checking type which was present among 2 patients. Reduced concentration, suicidal ideation and anhedonia were present each among 5(55.6\%) patients. Depression was the most common co-morbidity reported among $5(55.6 \%)$ patients. Severity of OCD was mild among $5(55.6 \%)$. Fluvoxamine was the most common drug [5(55.6\%)] used to treat OCD. Outcome of treatment was reported poor among $3(33.3 \%)$ patients. It was good/moderate among $1(25 \%)$ patient residing in urban area in comparison to $5(100 \%)$ from rural areas $(\mathrm{p}=0.048)$. Conclusion: Mean age of onset was found to be delayed among patients probably due to delay in identification of OCD. Hence awareness generation and early screening need to be initiated for early identification of OCD. The majority of OCD patients had positive history of suicide ideation and depression as co-morbidity, indicating the
\end{abstract}

need of screening patients for these conditions.

Keywords Obsessive Compulsive Disorder, Risk factors, Clinical Features, Management

\section{Introduction}

Obsessive-compulsive disorder (OCD) is the fourth most common mental illness following phobias, substance abuse and depression. [1] Two out of every three patients develop OCD at an early age.[2] OCD is associated with less likelihood of completion of elementary school education [3], lower rates of marriage [4], less work productivity [5], disability, higher rates of unemployment, and a wide range of functional impairments [5]. It therefore adversely affects the quality of life of the patients. [6] It also makes the OCD affected person easily dependent on others and thereby impacts their family life much more than other anxiety disorders. [2] In spite of the long term problems associated with OCD, it has not yet received the due attention of clinicians, researchers and policy makers. [1]

More than half of the OCD patients experience two or more co-morbid psychiatric conditions during their lifetime. [1] It is associated with high rates of major depression, social phobia [7], schizophrenia [8], bipolar disorder [8], and poor long-term social adjustment [9]. People may fear stigmatisation at work place, and often have concerns about disclosing its presence to their employers, family members and friends.[10] This could be the reason behind its under diagnosis. Poor insight and 
difficulty in differentiating it from normative rituals are possible reasons for its delayed diagnosis. [11]

OCD was selected for this research study as it is a commonly under diagnosed psychiatric disorder in the current setting. Hence awareness needs to be created regarding clinical presentation of this condition among the general public. This will ensure its early diagnosis and intervention which would also enable better treatment outcome among the affected.

Diagnostic challenge has been noted in OCD due to heterogeneous presentation of symptoms among patients.[12] The detection rate for OCD in primary care settings is unsatisfactory.[10] Studies done even at sophisticated health care set ups in developed countries have reported that a good number of OCD patients fail to receive appropriate medications, adequate treatment, conservative management or evidence based care. $[13,14]$ Identification of its epidemiological and other risk factors will help in planning long term preventive measures among high risk groups prone to develop OCD. Hence this study was done to assess the risk factors, clinical features and management practices of OCD in a tertiary care hospital in Mangalore city of south India.

\section{Literature Review}

A cross-sectional study was done at an OCD clinic in a tertiary care hospital in Bangladesh. Data were collected by interviewing OCD patients visiting the clinic from January 2016 to July 2017. The mean age of the respondents was $25.0 \pm 7.1$ years. In relation to socio demographic variables, $65 \%$ patients were males, $72 \%$ were unmarried, $64 \%$ were from rural areas, and $57 \%$ were students. Family history of mental illness was present among $45 \%$ patients. History of smoking was present among $26 \%$ patients. Obsession about dirt and contamination were found in $47 \%$ while compulsion regarding cleaning practices was found in $41 \%$ patients. Severity of OCD was assessed by Y-BOCS scores. As many as $12 \%$ patients had extremely severe OCD and $36 \%$ patients had severe OCD. [15]

A record based study was done among children/adolescent patients aged up to 17 years at a tertiary care hospital in India. Data were collected from January 1998 to December 2014. Mean age the patients was $12.8 \pm 2.5$ years. In relation to other socio-demographic variables, $72.1 \%$ were males and $77.8 \%$ were from urban areas. The most common comorbid disorder was depression which was reported among $13.5 \%$ patients. As many as $20.2 \%$ patients had poor insight. The mean age at onset of OCD was $10.7 \pm 3.0$ years. The OCD subtypes were predominantly obsessive, predominantly compulsive and mixed, observed among $7.6 \%, 7.4 \%$ and $85 \%$ patients respectively. Among the obsessions, contamination was present among $43.1 \%$ and among the compulsions, washing and cleaning type was present among $40.1 \%$ patients. Majority of the patients $(73.2 \%)$ were treated with Fluoxetine. The most common management modality was combination of exposure and response prevention (ERP), cognitive behavioral therapy (CBT) with Serotonin reuptake inhibitor (SRI) tried among $32.8 \%$ patients. [16]

A Finnish Hospital Discharge Register based study was done in Finland between January 1987 and December 2001. The mean age of male OCD patients was $14.8 \pm 4.3$ years and of female OCD patients was $15.6 \pm 3.9$ years. The proportion of males was $47 \%$. The most common co-morbidities in these patients were anxiety disorders followed by depressive disorders and psychotic disorders. Urban area as birth place was observed to be an independent risk factor for OCD in adjusted analysis. [17]

A study was done among OCD patients visiting the psychiatry outpatient department of a medical college hospital in India from January to June 2009. The mean age of these patients was $29.3 \pm 7.6$ years. Among them, $63.3 \%$ were males, $46.7 \%$ were unmarried, $53.3 \%$ were unemployed and $76.7 \%$ were from urban areas. More than one-third of these patients (36.7\%) had family history of psychiatric disorders. As many as $30 \%$ OCD patients had at least one episode of attempted suicide in the recent past. In Y-BOCS assessment, $43.3 \%$ had extremely severe and $23.3 \%$ patients had severe OCD. The most common obsession was fear of contamination and the most common compulsion was washing reported each among 43.3\% patients. As many as $46.7 \%$ patients spent more than three hours but less than 8 hours every day on obsessions. Similarly $46.7 \%$ patients had impaired levels of functioning and an identical proportion of them had severe distress due to their obsessions. Almost three-fourth (73.3\%) of these patients had no control over their obsessions while $63.3 \%$ patients completely yielded to their obsessions. [1]

\section{Materials and Methods}

This hospital record based retrospective cross-sectional study was done in the month of June 2018 in a tertiary care private hospital in Mangalore. Ethical approval was obtained from institutional ethics committee.

Subsequently, permission from the medical superintendent was obtained to go through the medical records of all OCD patients admitted in the psychiatry wards over the past ten years starting from January 2008. The medical records of patients with OCD were identified in the computer using the ICD code F42. These patients were confirmed to have diagnosed with OCD by the psychiatrists at this hospital.

The research questions were comprised of what were the common risk factors, clinical presentations and management practices among OCD patients in the current setting.

To obtain answers to these research questions, the 
secondary data related to OCD from the medical records were recorded in a semi-structured proforma. Various information like age at onset of OCD, type of OCD, socio-demographic details, risk factors of OCD like past history of traumatic brain injury, history of substance abuse, family history of OCD, types of co-morbidities, height, weight, body mass index (BMI), clinical presentations of OCD, investigations, non-pharmacological and pharmacological management modalities, compliance with treatment and outcome of treatment in the patients were noted down by the investigators. The proforma was self-designed with the help of review of literature. It was later content validated with the help of subject experts.

Data entry and analysis were done using Statistical Package for Social Sciences (SPSS Inc., Chicago, IL, USA) version 17.0.

Fisher's exact test was used to test association. $\mathrm{p}$ value less than 0.05 was taken as significant association.

Severity of OCD in the patients was assessed using Yale Brown Obsessive Compulsive Scale (Y-BOCS) scores as stated in the patient records. It was categorized as subclinical if the total severity score ranged from $0-7$, mild if it ranged from 8-15, moderate if it ranged from 16-23, severe if it ranged from 24-31 and extreme if it ranged from 32-40.[18]

Y-BOCS is the gold standard instrument to assess severity of OCD.[19] It is widely used to assess severity of OCD in both adults and children worldwide.[20] It includes five items each to assess obsessions and compulsions. Each item in relation to time, interference, distress, control and resistance is rated on a scale from 0 (none) to 4 (extreme). The scale has good psychometric properties and its inter-rater reliability and internal consistency values are more than 0.9.[21]

Outcome with treatment was considered good, moderate or poor improvement if the patient had stated in the medical records, more than $50 \%$, between 30 to $50 \%$ and less than $30 \%$ improvement respectively in comparison to their baseline state on admission.

\section{Results}

There were nine cases of OCD admitted at this hospital over the previous ten years. Mean age of these patients was $32.8 \pm 19.4$ years with age ranging from 12 to 65 years. Majority of the patients were males $(66.7 \%)$, were unmarried $(77.8 \%)$ and were from rural areas $(55.6 \%)$. (Table 1). Three out of the 9 patients were children/adolescents and they were all males. Mean age of children/adolescents was $15.7 \pm 3.5$ years. Mean age of the onset of OCD among participants was $27.9 \pm 15.2$ years with age ranging from 12 to 58 years. Four patients were diagnosed after 30 years of age. Mean age at onset of OCD among males $(\mathrm{n}=6)$ was $26.2 \pm 17.8$ years and among females ( $\mathrm{n}=3$ ) was $31.3 \pm 10.3$ years. There was no association between gender and age of the onset of OCD $<18$ years $(\mathrm{p}=0.4643)$. Mean age of the onset of OCD among children/adolescents was $14.3 \pm 2.5$ years.

Table 1. Socio demographic distribution of study participants

\begin{tabular}{|c|c|c|}
\hline & Number & Percentage \\
\hline \multicolumn{3}{|c|}{ Age group (years) } \\
\hline$<15$ & 1 & 11.1 \\
\hline $15-34$ & 4 & 44.5 \\
\hline $35-54$ & 2 & 22.2 \\
\hline $55-64$ & 1 & 11.1 \\
\hline$\geq 65$ & 1 & 11.1 \\
\hline \multicolumn{3}{|c|}{ Age at the onset of OCD (years) } \\
\hline$<15$ & 2 & 22.2 \\
\hline $15-34$ & 4 & 44.5 \\
\hline $35-54$ & 2 & 22.2 \\
\hline$\geq 55$ & 1 & 11.1 \\
\hline \multicolumn{3}{|l|}{ Gender } \\
\hline Males & 6 & 66.7 \\
\hline Females & 3 & 33.3 \\
\hline \multicolumn{3}{|l|}{ Marital status } \\
\hline Unmarried & 7 & 77.8 \\
\hline Married & 2 & 22.2 \\
\hline \multicolumn{3}{|c|}{ Educational status $(n=4)$} \\
\hline Graduate & 2 & 50.0 \\
\hline Pre University & 1 & 25.0 \\
\hline Primary school & 1 & 25.0 \\
\hline \multicolumn{3}{|c|}{ Occupational status } \\
\hline Skilled & 1 & 11.1 \\
\hline Semi-skilled & 1 & 11.1 \\
\hline Housewife & 3 & 33.4 \\
\hline Student & 2 & 22.2 \\
\hline Retired & 1 & 11.1 \\
\hline Unemployed & 1 & 11.1 \\
\hline \multicolumn{3}{|l|}{ Type of family } \\
\hline Nuclear & 6 & 66.7 \\
\hline Joint family & 3 & 33.3 \\
\hline \multicolumn{3}{|l|}{ Place of residence } \\
\hline Urban & 4 & 44.4 \\
\hline Rural & 5 & 55.6 \\
\hline Total & 9 & 100.0 \\
\hline
\end{tabular}

The median duration of OCD was 2 years with an Inter Quartile range of 1.5 to 8.5 years. The mean duration of OCD was $4.9 \pm 5.9$ years. Among the adult patients, 4 out of 6 were unmarried.

The most common risk factor of OCD identified in this study was family history of OCD. It was observed among three patients. Among them, it was positive in the maternal 
uncle and in the sister in one patient each. In one of the patient files, it was not specified as to who in the family had history of OCD. (Table 2) There was no association between family history of OCD with age at the onset of $\mathrm{OCD}<18$ years among the patients $(\mathrm{p}=1)$.

Table 2. Distribution of risk factors of obsessive compulsive disorder (OCD) among patients $(\mathrm{n}=9)$

\begin{tabular}{|l|c|c|}
\hline Risk factors & Number & Percentage \\
\hline Family history of OCD & 3 & 33.3 \\
\hline Habituated to consuming alcohol & 2 & 22.2 \\
\hline Family history of other mental illnesses & 1 & 11.1 \\
\hline Past history of OCD academic & 1 & 11.1 \\
\hline $\begin{array}{l}\text { Precipitates during } \\
\text { examinations }\end{array}$ & 1 & 11.1 \\
\hline Breath holding spells in childhood & 1 & 11.1 \\
\hline $\begin{array}{l}\text { History of difficult temperament in } \\
\text { childhood }\end{array}$ & 1 & 11.1 \\
\hline Past history of postpartum depression & 1 & 11.1 \\
\hline $\begin{array}{l}\text { Past history of having suffered physical } \\
\text { abuse }\end{array}$ & 1 & 11.1 \\
\hline $\begin{array}{l}\text { Past history of having suffered sexual } \\
\text { abuse }\end{array}$ & 1 & 11.1 \\
\hline Past history of suicidal attempt & 1 & 11.1 \\
\hline Work related pressure & 11.1 \\
\hline Habituated to smoking & 1 & \\
\hline
\end{tabular}

Family history of other mental illnesses comprised of presence of anxiety disorder in maternal grandmother of a patient with OCD.

The most common type of obsession was sexual, reported among 3 patients. This was followed by obsession of alignment in perfect symmetry, of contamination and of blasphemous thoughts which were reported among 2 patients each. Intrusive thought regarding something bad is going to happen to the offspring and regarding dysmorphic disorder of genital organs as a result of masturbation was present in 1 patient each.

The other types of obsessions were thoughts of being possessed, concerns about welfare of family members, somatic obsessions, regarding difficulty in swallowing, regarding fear of stoppage of breathing, being pre occupied with a work till it is completed, obsessional rumination, repeated thoughts of self-blame, obsession regarding forgetfulness (to feed children, to turn gas stove off), slowness with work, which were reported among 1 patient each.

The number of obsessions was reported to be $6,5,3$ and 2 among one patient each. The other five patients had a single obsession each.

Four patients have spent less than 1 hour (Grade 1), one patient has spent 1 to 3 hours (Grade 2) and 4 other patients have spent 3 to 8 hours per day (Grade 3 ) on obsessive thoughts.

Four patients have less than 1 consecutive hour, 4 other patients have 1 to 3 consecutive hours and 1 patient has 3 to
8 consecutive hours per day of obsession free intervals.

Four patients have substantial interference (Grade 3), 4 other patients have moderate but manageable interference (Grade 2) and 1 patient has mild interference (Grade 1) with occupational or social activities due to OCD.

Eight patients have moderate but manageable (Grade 2) and 1 patient has little (Grade 1) distress from obsessions.

Eight patients have some resistance (Grade 2) while 1 patient has much resistance to obsessions (Grade 1).

Three patients have no control over obsessions (Grade 4). They feel that this behavior was completely involuntary and are unable to alter it. Three patients have little control over obsessions (Grade 3). They can only divert attention with anxiety. The rest three patients have some control over their obsessional thoughts (Grade 2).

Compulsions were present among 3(33.3\%) patients. One patient had five compulsions, one had three and one had a single type of compulsion. The most common compulsion was checking which was present among 2 patients. It involved checking of stove and locks and checking related to somatic obsessions in two patients each and checking of only stove and locks, repeated reading, repeated swallowing of saliva, counting in multiples and perfect completion of any work reported in one patient each.

One patient had compulsion of repeating rituals of reading and writing. Another patient had the compulsion of repeated hand washing and repeated reading of the same article in the newspaper. One patient had the compulsion of repeated smelling of solvents like sprays.

One patient spent less than an hour (Grade 1), 1 patient spent 3 to 8 hours (Grade 3 ) and 1 patient spent more than 8 hours per day (Grade 4) on compulsions.

One patient had 3 to 8 hours (Grade 2) and 2 patients had more than 8 hours per day (Grade 1) of compulsion free intervals.

One patient had substantial (Grade 3 ) and 2 patients had manageable (Grade 2) interference with social or occupational performance.

One patient had moderate but manageable (Grade 2) and 2 patients had mild (Grade 1) distress from compulsions.

Two patients reported to have some effort to resist compulsions (Grade 2) while 1 patient reported yielding to compulsions often (Grade 3).

Two patients experienced an inner feeling of increase in anxiety and 1 patient experienced disturbing increase in anxiety if compulsions were resisted.

Two patients reported control over compulsions to some extent (Grade 2), while 1 patient reported minimal control and being overpowered by compulsions (Grade 3 ).

Out of the 9 patients, 6 had predominantly obsessions while the rest 3 had mixed type. Among the patients presenting with mixed type, 2 were children/adolescents.

The miscellaneous symptoms reported among OCD patients were delusions (1), presence of superstitious beliefs (1), difficulty in swallowing (1), irritability (1), 
dysarthria (1), excessive masturbation (1), daytime sleepiness (1), burning sensation in the feet (1), burning micturition (1), fearfulness (1), palpitations (1) and wetting of undergarments (1).

Four (44.4\%) patients reported poor (Grade 4) insight. The rest 5 patients had the ability to recognize own mental illness.

The most common clinical features were reduced concentration, suicidal ideation and anhedonia seen among 5 patients each. Out of the two patients with hallucinations, one had visual type and the other patient had visual, auditory, tactile and somatic type of hallucinations. (Table 3)

Table 3. Clinical features and comorbidities reported among OCD patients $(\mathrm{n}=9)$

\begin{tabular}{|c|c|c|}
\hline & Number & Percentages \\
\hline \multicolumn{3}{|l|}{ Clinical features } \\
\hline Reduced concentration & 5 & 55.6 \\
\hline Suicidal ideation & 5 & 55.6 \\
\hline Anhedonia & 5 & 55.6 \\
\hline Fatigue & 4 & 44.4 \\
\hline Disturbed sleep & 3 & 33.3 \\
\hline Reduced appetite & 2 & 22.2 \\
\hline Pain while swallowing & 2 & 22.2 \\
\hline Hallucinations & 2 & 22.2 \\
\hline Insomnia & 2 & 22.2 \\
\hline Joint pains and body aches & 2 & 22.2 \\
\hline \multicolumn{3}{|l|}{ Co-morbidities } \\
\hline Depression & 5 & 55.6 \\
\hline Anxiety disorder & 2 & 22.2 \\
\hline Seizures & 2 & 22.2 \\
\hline Paraphilia & 2 & 22.2 \\
\hline Migraine & 2 & 22.2 \\
\hline Dhat syndrome & 2 & 22.2 \\
\hline Diabetes mellitus & 2 & 22.2 \\
\hline
\end{tabular}

Suicide ideation symptom was observed among $4(80 \%)$ out of 5 patients with depression.

The various other co-morbidities reported among OCD patients were alopecia (1), trichotillomania (1), tinea infection (1), seborrheic dermatitis (1), hypothyroidism (1), hypertension (1), fatty liver (1), refractive error (1), hysterectomy (1), sub-syndrome panic (1), paranoid schizophrenia (1), psychogenic erectile dysfunction (1), mixed disorders of conduct and emotions (1), squint (1), deviated nasal septum (1), turbinate hypertrophy (1) and obesity (1).

Among the males, 2 had depression, while among the females, all 3 had depression $(\mathrm{p}=0.1667)$. Two of the patients with depression had recurrent depressive disorder.

Out of the 4 patients with poor insight, 1 was an adolescent and 2 were female patients. There was no association of presence of poor insight in OCD patients with age at the onset of OCD $<18$ years $(\mathrm{p}=1)$, presence of depression $(\mathrm{p}=0.524)$, presence of schizophrenia $(\mathrm{p}=0.444)$, severity of OCD $(\mathrm{p}=0.595)$ or with the treatment outcome $(\mathrm{p}=0.595)$.

Mean number of co-morbidities reported among the patients was $7.2 \pm 2.9$ with number of co-morbidities ranging from 2 to 13 . The mean number of co-morbidities among male patients $(\mathrm{n}=6)$ was $7.3 \pm 3.5$ and among female patients $(\mathrm{n}=3)$ was $7.0 \pm 2.0$. Three $(33.3 \%)$ patients complained that their academic performance was affected because of OCD. (Table 4)

Table 4. Distribution of personal and family related problems reported by patients as a result of OCD $(\mathrm{n}=9)$.

\begin{tabular}{|l|c|c|}
\hline Problems & Number & Percentage \\
\hline Studies being affected & 3 & 33.3 \\
\hline $\begin{array}{l}\text { Feeling that after marriage, sex life will } \\
\text { be unsuccessful }\end{array}$ & 2 & 22.2 \\
\hline Guilt feeling & 2 & 22.2 \\
\hline Forgets important tasks & 1 & 11.1 \\
\hline Scolds parents/elders & 1 & 11.1 \\
\hline Excessive television viewing & 1 & 11.1 \\
\hline $\begin{array}{l}\text { Feeling incapable of handling } \\
\text { responsibilities in life }\end{array}$ & 1 & 11.1 \\
\hline $\begin{array}{l}\text { Gets constantly disturbed with thoughts } \\
\text { of career and settlement in life }\end{array}$ & 1 & 11.1 \\
\hline Shows cruelty to animals in frustration & 1 & 11.1 \\
\hline Says lies repeatedly & 1 & 11.1 \\
\hline $\begin{array}{l}\text { Spends lot of time over telephonic } \\
\text { conversations }\end{array}$ & 1 & 11.1 \\
\hline
\end{tabular}

One out of the 9 patients had undergone electroencephalogram examination. It showed features of centro-parietic epileptiform discharges bilaterally.

All 9 patients were screened by Y-BOCS. The Y-BOCS scores of three patients with mixed OCD was 22, 24 and 29 indicating one with moderately severe OCD and two others with severe OCD. Among the other 6 patients, 5 had mild OCD and 1 had subclinical OCD.

Both the patients with severe OCD were children/adolescents $(\mathrm{p}=0.0833)$. The patient with moderately severe OCD was an adult. Mean age at onset among patients with severe $\operatorname{OCD}(\mathrm{n}=2)$ was $15.5 \pm 2.1$ years in comparison to $31.4 \pm 15.5$ years among patients with sub clinical/mild/moderately severe OCD. There was no association between age at the onset of OCD before 18 years with presence of severe OCD among patients $(\mathrm{p}=0.0833)$. Two (33.3\%) males had severe OCD in comparison to none among female OCD patients $(\mathrm{p}=0.5)$.

One patient underwent mini mental state examination. The score obtained was 29 indicating normal cognition in this patient.

Non pharmacological methods of managing OCD were tried among $4(44.4 \%)$ patients. Counselling and diversional therapy were the most common non pharmacological methods, tried among 2 patients each. 
Fluvoxamine was the most common drug used to treat OCD among 5(55.6\%) patients. (Table 5)

Table 5. Distribution of management practices among OCD patients $(\mathrm{n}=9)$

\begin{tabular}{|c|c|c|c|}
\hline Treatment modalities & Number & Percentage & \\
\hline \multicolumn{4}{|l|}{ Non pharmacological } \\
\hline Counselling & 2 & 22.2 & \\
\hline Diversional therapy & 2 & 22.2 & \\
\hline Yoga & 1 & 11.1 & \\
\hline $\begin{array}{c}\text { Cognitive Behavioral } \\
\text { therapy }\end{array}$ & 1 & 11.1 & \\
\hline Relaxation therapy & 1 & 11.1 & \\
\hline Couple therapy & 1 & 11.1 & \\
\hline $\begin{array}{c}\text { Medications used to } \\
\text { treat OCD }\end{array}$ & & & $\begin{array}{c}\text { Dosage (mg } \\
\text { per day) }\end{array}$ \\
\hline Fluvoxamine & 5 & 55.6 & 25 to 100 \\
\hline Clomipramine & 2 & 22.2 & 50 \\
\hline Fluoxetine & 2 & 22.2 & 20 to 100 \\
\hline Sertraline & 2 & 22.2 & 25 to 100 \\
\hline Clonazepam & 2 & 22.2 & 0.125 to 1 \\
\hline Escitalopram & 2 & 22.2 & 20 \\
\hline Paroxetine hydrochloride & 1 & 11.1 & 31.25 \\
\hline \multicolumn{4}{|l|}{$\begin{array}{l}\text { Medications used to } \\
\text { treat comorbidities }\end{array}$} \\
\hline Lorazepam & 4 & 44.4 & 2 \\
\hline Etizolam & 2 & 22.2 & 0.75 to 1 \\
\hline Alprazolam & 2 & 22.2 & 0.25 to 0.5 \\
\hline Propranolol & 2 & 22.2 & 20 to 40 \\
\hline
\end{tabular}

Two patients with severe OCD were managed using Fluvoxamine alone. Another patient with moderately severe OCD was treated with both Fluvoxamine and Clomipramine. These two drugs were also prescribed to a patient with mild OCD. Out of the nine patients, four were treated with single drug, three with 2 drugs and one patient received three drugs for the management of OCD.

One patient aged 12 years, with sub clinical OCD, was neither managed with any medications specific for OCD nor by any other non-pharmacological methods. One adolescent was managed with a combination of CBT, yoga therapy and Fluvoxamine while the other was managed with counselling, diversional therapy and Fluvoxamine.

CBT and yoga therapy were used for management of one of the patients with severe OCD while the other with severe OCD received counselling and diversional therapy. However, the patient who had moderately severe OCD did not receive any non-pharmacological management.

Other medications used by patients for the treatment of co-morbidities were Risperidone (1), Trihexiphenidyl (1), Metformin (1), Levothyroxine (1), Amlodipine (1), Mirtazipine (1), Divalproex (1), Vitamin B 12 (1), Sodium valproate (1), Lurasidone (1), Amisulpride (1) and Armodafinil (1).
Indications for these medications were for reasons like management of depression associated with failure in exams, treatment of schizophrenia/bipolar disorders, treatment of anxiety, treatment of migraine, and to promote wakefulness in those with extreme daytime sleepiness.

Poor compliance with treatment was reported in 1 patient with mild OCD who was an adult female patient.

Alternative system of medicine namely ayurveda and homeopathy was taken by one of the patients for the treatment of OCD. This patient had reported moderate improvement with treatment outcome.

Two patients adopted a supportive measure for the management of OCD in the form of sharing problems related to OCD with their friends. One patient even felt relieved of symptoms related to OCD by consuming alcohol.

Outcome with treatment was reported good, moderate, minimal and no improvement among 5, 1,2 and 1 patient respectively.

Outcome of treatment was good/moderate among 1(25\%) of the patient from urban areas in comparison to $5(100 \%)$ from rural areas $(\mathrm{p}=0.048)$.

Outcome with treatment was not associated with age of the participant (below 18 years) $(\mathrm{p}=1)$, age at the onset of OCD (below 18 years) $(p=1)$, gender $(p=0.464)$, marital status $(\mathrm{p}=0.5)$, type of family $(\mathrm{p}=1)$, past history of OCD $(\mathrm{p}=0.333)$, family history of $\mathrm{OCD}(\mathrm{p}=0.226)$, family history of other mental illnesses $(p=0.333)$, multiple number of obsessions $(\mathrm{p}=1)$, multiple number of compulsions $(\mathrm{p}=1)$, number of co-morbidities exceeding seven $(p=1)$, BMI $(p=1)$, duration of OCD more than 2 years $(p=1)$ and with severity of $\mathrm{OCD}(\mathrm{p}=0.226)$.

\section{Discussion}

Identification of risk factors of OCD will help health care providers in identification of high risk groups. In this study, majority of the patients were males as also reported in several other studies, where the proportion of males were $53 \%$ [22], 54.7\% [23], 60\% [24], 63.3\% [1], and 65\% [15]. These findings were however contrary to the observations in studies done in USA [25] where $51.6 \%$, in Germany [26] where $73.7 \%$ and in Finland [12] where 53\% were females. All the patients who were children/adolescents in this study were males compared to $71.7 \%$ reported in a study done in Bangladesh. [27] It has been reported that in pre-pubertal years males predominate [5] but after adolescence presence of OCD is more among women [28].

The mean age of onset of OCD among children/adolescents in earlier studies was 9.5 years [29], 9.8 years [30], 13.2 years [31], 13.8 years [30] in comparison to 14.3 years in the present study. Early age at onset particularly during schooling years has significance. This is because patients with onset of OCD before the age of 18 years were found to have poor educational attainment 
compared to those patients with later onset. [3]

Overall mean age of onset of OCD in this study was 27.9 years compared to 19.4 years [26], 19.5 years [32] and 23.4 years [22] in previous studies. The onset of OCD after the age of 30 years has been reported to be very uncommon. [32] In the current setting since $44.4 \%$ patients were identified with OCD after the age of 30 years, there is a possibility of diagnostic delay among these patients. Hence awareness of OCD needs to be improved in the current setting.

The mean age of onset was later in females in this study as also supported by the findings of American Psychiatric Association. [5] Late-onset OCD patients are reported to perform poorly with respect to the immediate and the delayed recall conditions compared to the early-onset OCD patients and controls.[33]

Majority of the OCD patients in this study were unmarried. In previous studies, the proportion of unmarried among the OCD affected were found to be $46.7 \%$ [1], 50\% [24], 68\% [22] and $72 \%$ [15]. This supports the observation that marriage rates are low among the people with OCD in comparison to the general population. [10]

Majority of patients (55.6\%) in this study were from rural area. Other studies reported $23.3 \%$ [1], 40\% [24], and $64 \%[15]$ as the proportion of OCD patients from rural area A Finnish study on the contrary found, subjects born in urban area to have significantly elevated risk of OCD in adjusted analysis, due to frequent referrals to mental health services. [17]

In this study, $66.7 \%$ presented with predominantly obsessions. The rest $33.3 \%$ patients presented with mixed OCD. In a study done in Taiwan, $75 \%$ patients presented with mixed OCD, $14 \%$ with predominantly obsessions and $11 \%$ with predominantly compulsions. [22] It has been reported that as many as $55 \%$ of individuals with OCD have predominantly obsessions.[34] In previous studies done among children/adolescents, $85 \%[16]$ and $85.7 \%[29]$ had presence of mixed OCD while 14.3\%[29] had predominantly compulsions. The proportion of the same reported in this study was $66.7 \%$ and nil respectively.

The most common type of obsessions in the present study was sexual type. In other studies the most common type was contamination which was present among $37 \%$ [22], 43.3\% [1] and 47\% [15] OCD patients. This meant that the most common presentation pattern of obsessions among patients in the current setting was different from that observed in other settings.

The most common type of compulsions in this study was the checking type which was also reported among 50\% patients in a study done in Taiwan [22] and $28.8 \%$ in literature [10]. However in few other studies, the most common compulsion was washing reported among $41 \%$ [15] and $43.3 \%$ [1] patients. This again meant that the most common presentation pattern of compulsions among patients in the current setting was different from that seen in other settings.
In the study done in Chennai, India, $46.7 \%$ patients spent 3 to 8 hours followed by $36.7 \%$ spent more than 8 hours every day on their obsessions. [1] Similarly the present study also observed that $44.4 \%$ patients spent 3 to 8 hours per day on their obsessions. The former study also reported $46.7 \%$ patients with impaired levels of functioning and $43.3 \%$ with incapacitating levels of interference due to their obsessions which was again similar to the observations in this study.[1] The Chennai, India based study also reported that $73.3 \%$ OCD patients had no control over their obsessions which was more than the findings of this study. Also their observation that $63.3 \%$ of OCD patients completely yielded to obsessions was in contrary to the present study findings where $88.9 \%$ of OCD patients reported some resistance and the rest $11.1 \%$ reported much resistance to their obsessions.[1] The proportion of patients with severe OCD in this study was $22.2 \%$ in comparison to $48 \%$ [15] and $66.6 \%$ [1] reported in previous studies. These observations infer that obsessions were less severe among patients in the present study compared to other studies. Similarly the proportion of severe OCD among children/adolescents was $66.7 \%$ in this study which was lesser than the proportion of $90 \%$ reported in the study done in Bangladesh.[27] However the proportion of children with severe OCD in the US based study was only $7.7 \%$ probably because of its early identification.[28]

Depression was the most common co-morbidity (55.6\%) in OCD patients in this study which was reported between $27 \%$ [15], 30\% [23], 38.6\% [17] and 41.5\% [22] OCD patients in previous studies. Most common co-morbidities among OCD affected patients in other studies were hypothyroidism [15], anxiety disorders [17, 32] and major depressive disorder [15, 23]. The number of co-morbidities reported among OCD patients in a US based study was none, single, two or more among $25 \%, 37 \%$ and $38 \%$ patients respectively.[28] In this study all patients had at least two co-morbidities. The treating doctor therefore needs to screen for common co-morbidities in OCD patients. Since majority of OCD patients in this study had depression, it becomes essential to early diagnose and treat the same along with OCD management.

Insight was reported to be poor among $44.4 \%$ OCD patients in the present study as compared to 15 to $36 \%$ in previous studies.[35,36] In the study done in Bangalore, India among children/adolescents, poor insight was reported in more than one-third of the subjects in comparison to one-fourth reported in this study.[16] Bellino et al observed that the presence of poor insight leads to delay in diagnosis of OCD, severe form of OCD, higher rates of depression, schizophrenia and poor treatment outcome.[37]

Suicidal ideation was present among 9.3\% [30], 20\% [15] and history of suicidal attempt among $11 \%$ [15], 20\% [30] and 30\% [1] OCD patients in previous studies. The present study reported similar history among $55.6 \%$ and $11.1 \%$ patients respectively. A Chennai, India based study 
even reported that, number patients with history of attempted suicide were more among those affected with OCD, in comparison to those with depression. [1] These observations emphasize the need of counselling activities among OCD patients.

Past history of having suffered physical and sexual abuse was present in 1 patient each in this study. This finding has been supported by previous studies which reported history of traumatic and stressful life events before the onset of OCD. $[5,38]$ These issues need to be again addressed during the counselling sessions.

In this study, family history of OCD was present in $33.3 \%$ patients compared to $6 \%$ reported in the Taiwanese study.[22] A meta-analytic review reported that OCD patients have four times higher risk to have another family member with OCD in comparison to controls.[39] This supports the genetic aetiology of this condition. Positive familial history of OCD in individuals diagnosed with OCD has been found to result in a higher rate of cognitive disruption too.[29] Early-onset OCD was found to be more familial than the adult-onset OCD in previous studies which was not supported by findings in this study. $[16,40]$

The family history of other mental illnesses in this study was present among $11.1 \%$ patients compared to other studies which reported it among 36.7\% [1] and 45\% [15] OCD patients. It has been reported that OCD spectrum of disorders like OCD, body dysmorphic disorder and Tourette syndrome share some of the same vulnerability genes. [2]

Alcohol consumption was reported among $22.2 \%$ and smoking among $11.1 \%$ OCD patients in this study. In other studies, smoking was reported among $26 \%$ [15] and substance abuse among 10\% [15], 20\%[1] and 30\%[41] OCD patients. Substance abuse has been reported to exacerbates OCD symptoms, limit insight, and deteriorate overall functioning among them.[42] Hence to improve treatment prognosis it becomes essential for the OCD patient to avoid various substances of abuse.

Fluvoxamine (Selective Serotonin Reuptake Inhibitor) was the most common drug used in the management of OCD. It was used in more than half of the patients in this study. Clomiphene (SRI) was used for management in $22.2 \%$ patients. Research has shown that patients get benefitted by drugs that increase the levels of serotonin in the brain. The main medications which increases the level of these neurotransmitters are SRIs and hence should have been the most commonly prescribed drug in the treatment of OCD.[2] These are also useful to treat depression and has been found to be more efficacious than SSRIs.[2] About 80 per cent of patients taking Clomipramine have reported good improvement in their condition.[2] The reason behind majority of patients in this study being treated with new SSRIs could be probably because of the more complicated side effects of Clomipramine.[2] The new SSRIs constitutes drugs like Fluvoxamine, Paroxetine and Sertraline which are well tolerated by patients and have minimal side effects.[10,19] Few patients in this study were found to be on combination of medications to manage OCD. It is not uncommon to manage OCD with two or three drugs before finding the one that works the best. [2]

The ideal treatment of OCD is a combination of CBT and drug therapy. [2] Combination of SSRIs with CBT which are recommended to be efficacious [43] was tried in only $11.1 \%$ patient in this study. The treatment of paediatric OCD as per established evidence base is by CBT with SSRIs. [44, 45] CBT in the present study was done for an adolescent OCD patient. It is associated with a $40 \%$ to $65 \%$ reduction in symptoms among paediatric OCD patients. [46] Fluvoxamine was the only drug used in management of children/adolescent OCD patients in this study. Randomized controlled trials have shown that SSRIs are effective and it reduces $29 \%$ to $44 \%$ of symptoms in paediatric OCDs and appear to be well tolerated and safe.[46] Both Sertraline and Fluvoxamine are licensed for use in children, with sertraline being more recommended because of its lesser side effects.[12] In severely ill patients, a combination of CBT and SSRI is recommended, which was not followed among one of the patient in this study.[19] ERP, cognitive therapy and thought record are some effective methods tried under CBT for OCD management.[2]

Outcome with treatment was reported to be moderate to good among $66.7 \%$ patients in this study. In another prospective study, it was reported that as much as $60 \%$ of OCD patients showed improvement in their condition within 10 years of treatment. However in about $20 \%$ patients there was either no improvement or deterioration of health condition.[47] British psychological society reported poor treatment outcomes among patients with early age of OCD onset, male patients and long duration of OCD which was not observed in this study.[10] Only the present study observed that the patients coming from rural areas had better treatment outcomes. This might be because of better social support mechanisms in rural areas compared to that in urban areas.

Relapse rate was reported as $25 \%$ by Skoog et al which was more than $11.1 \%$ observed in this study.[47] Poor compliance with treatment was reported in 1 patient in this study. Poor compliance with treatment was found to increase the risk of relapse among OCD patients after recovery from the disease.[2] Hence patients need to be educated regarding this aspect.

The patient who was an alcoholic in the present study was also taking alprazolam for the relief of anxiety. Care needs to be taken while prescribing benzodiazepines in patients with alcohol or other substance usage as this poses a risk of abuse and can be hazardous too.[2]

The patient who was undergoing CBT was also on treatment with clonazepam and propranolol combination tablet for management of migraine. Here again benzodiazepines can affect short-term memory and learning [2], and can also interfere with habituation to the 
anxiety and hence could have been avoided.

In this study, combination of Clomipramine and Fluvoxamine was prescribed in 2 patients. Clomipramine is an effective augmenting agent with SSRIs in management of OCD.[19] However it should be used cautiously with Fluoxetine and Fluvoxamine as it may increase the risk of serotonin syndrome and Clomipramine related adverse effects.[19]

\section{Conclusions}

The mean age at onset of OCD among patients in the current setting was delayed. This might have been as a result of its delayed diagnosis. Hence awareness generation and screening methods need to be initiated for the early identification and management of this underdiagnosed psychiatric disorder. Family history of OCD was reported among one third of the patients. More than half of the OCD patients had positive history of suicidal ideation and depression as a co-morbidity. Hence it is essential to look for depression in OCD and manage it accordingly in order to prevent suicidal attempts. Majority of the patients had predominantly obsessions type of OCD. The most common type of obsession was of sexual type and the most common compulsion reported was the checking type. Fluvoxamine was the most common drug used to treat OCD. Outcome of treatment was reported poor (minimal/no improvement) among one third of the patients. More research need to be done at the current setting to find out the reason behind poor treatment outcomes among OCD patients from urban areas.

\section{Limitations}

The sample size was small as the study reports the findings among OCD patients admitted at a single tertiary care centre. Further large-scale studies preferably community based would have been ideal but time and resources constraints did not permit such a design. There were also missing information on certain parameters in the medical case records.

\section{Conflict of Interest}

None declared.

\section{REFERENCES}

[1] Raman J, Elangovan S, Manickam T. A Comparative Study of Socio Demographic and Clinical Profiles in Patient with Obsessive Compulsive Disorder and Depression. American Journal of Psychiatry and Neuroscience 2018; 6: 99-103.
[2] Rector NA, Bartha C, Kitchen K, Katzman M, Richter M. Obsessive Compulsive Disorder. Toronto: Centre for Addiction and Mental Health; 2001.

[3] Perez-Vigil A, Fernández de la Cruz L, Brander G, Isomura $\mathrm{K}$, Jangmo A, Feldman I, et al. Association of Obsessive-Compulsive Disorder With Objective Indicators of Educational Attainment: A Nationwide Register-Based Sibling Control Study. JAMA Psychiatry. 2018; 75: 47-55.

[4] Magliano L, Tosini P, Guarneri M, Marasco C, Catapano F: Burden on the families of patients with obsessive-compulsive disorder: a pilot study. Eur Psychiatry. 1996; 11: 192-7.

[5] American Psychiatric Association. What Is Obsessive Compulsive Disorder? https://www.psychiatry.org/patientsfamilies/ocd/what-is-obsessive-compulsive-disorder[Cited 4th July, 2019]

[6] Huppert JD, Simpson HB, Nissenson KJ, Liebowitz MR, Foa EB. Quality of life and functional impairment in obsessive-compulsive disorder: a comparison of patients with and without comorbidity, patients in remission, and healthy controls. Depress Anxiety. 2009; 26: 39-45.

[7] Black DW, Noyes R Jr. Comorbidity and obsessive-compulsive disorder. In: Maser JD, Cloninger CR, editor. Comorbidity of Mood and Anxiety Disorders. Washington, DC: American Psychiatric Press; 1990, p. 305 16.

[8] Cederlof M, Lichtenstein P, Larsson H, Boman M, Ruck C, Landen M, et al. Obsessive-compulsive disorder, psychosis, and bipolarity: A longitudinal cohort and multigenerational family study. Schizophr Bull. 2015; 41: 1076-83.

[9] Bolton D, Luckie M, Steinberg D. Long-term course of obsessive-compulsive disorder treated in adolescence. J Am Acad Child Adolesc Psychiatry 1995; 34: 1441-50.

[10] The British Psychological Society and the Royal College of Psychiatrists. Obsessive compulsive disorder: Core interventions in the treatment of obsessive compulsive disorder and body dysmorphic disorder. National Collaborating Centre for Mental Health commissioned by the National Institute for Health and Clinical Excellence: London; 2006.

[11] Evans DW, Leckman JF, Carter A, Reznick JS, Henshaw D, King RA, et al. Ritual, habit, and perfectionism: the prevalence and development of compulsive-like behavior in normal young children. Child Dev 1997; 68: 58-68.

[12] Krebs G, Heyman I. Obsessive-compulsive disorder in children and adolescents. Arch Dis Child. 2015; 100: 495-9.

[13] Chowdhury U, Frampton I, Heyman I. Clinical characteristics of young people referred to an obsessive compulsive disorder clinic in the United Kingdom. Clin Child Psychol Psychiatry. 2004; 9: 395-401.

[14] Blanco C, Olfson M, Stein DJ, Simpson HB, Gameroff MJ, Narrow WH. Treatment of obsessive-compulsive disorder by U.S. psychiatrists. J Clin Psychiatry. 2006; 67: 946-51.

[15] Algin S, Arafat YSM. Symptom profile of hundred patients with obsessive-compulsive disorder in a tertiary care hospital of Bangladesh. EC Psychology and Psychiatry 2019; 8: 4-8. 
[16] Deepthi K, Sagar Kommu JV, Smitha M, Reddy YC. Clinical profile and outcome in a large sample of children and adolescents with obsessive-compulsive disorder: A chart review from a tertiary care center in India. Indian $\mathrm{J}$ Psychiatry. 2018; 60: 205-12.

[17] Rintala H, Chudal R, Leppamaki S, Leivonen S, Hinkka-Yli-Salomaki S, Sourander A. Register-based study of the incidence, comorbidities and demographics of obsessive-compulsive disorder in specialist healthcare. BMC Psychiatry 2017; 17: 64.

[18] Y-BOCS Symptom Checklist. Available from:https://psych res.washington.edu/clinicaltools/ybocs.pdf

[19] Janardhan Reddy YC, Sundar AS, Narayanaswamy JC, Math SB. Clinical practice guidelines for obsessive-compulsive disorder. Indian J Psychiatry. 2017; 59: 74-90.

[20] Scahill L, Riddle MA, McSwiggin-Hardin M, Ort SI, King RA, Goodman WK, et al. Children's Yale Brown Obsessive Compulsive Scale: reliability and validity. J Am Acad Child Adolesc Psychiatry. 1997; 36: 844-52.

[21] Goodman WK, Price LH, Rasmussen SA, Mazure C, Delgado P, Heninger GR, et al. The Yale-Brown Obsessive Compulsive Scale. II. Validity. Arch Gen Psychiatry. 1989; 46: 1012-6.

[22] Juang YY, Liu CY. Phenomenology of obsessive-compulsive disorder in Taiwan. Psychiatry Clin Neurosci. 2001; 55: 623-7.

[23] Benatti B, Dell'Osso B, Arici C, Hollander E, Altamura AC. Characterizing impulsivity profile in patients with obsessive-compulsive disorder. Int J Psychiatry Clin Pract. 2014; 18: 156-60.

[24] Kohli A, Rana DK, Gupta N, Kulhara P. Neuropsychological assessment in obsessive-compulsive disorder. Indian $\mathrm{J}$ Psychol Med. 2015; 37: 205-11.

[25] Patel SR, Humensky JL, Olfson M, Simpson HB, Myers R, Dixon LB. Treatment of obsessive-compulsive disorder in a nationwide survey of office-based physician practice. Psychiatr Serv. 2014; 65: 681-4.

[26] Martin V, Huber M, Rief W, Exner C. Comparative cognitive profiles of obsessive-compulsive disorder and schizophrenia. Arch Clin Neuropsychol. 2008; 23: 487-500.

[27] Chowdhury MH, Mullick MS, Arafat SM. Clinical profile and comorbidity of obsessive-compulsive disorder among children and adolescents: A cross-sectional observation in Bangladesh. Psychiatry J. 2016; 2016: 9029630

[28] Fireman B, Koran LM, Leventhal JL, Jacobson A. The prevalence of clinically recognized obsessive-compulsive disorder in a large health maintenance organization. Am J Psychiatry. 2001; 158: 1904-10.

[29] Baykal S, Karabekiroglu K, Senses A, Karakurt MN, Calik T, Yuce M. Neuropsychological and clinical profiles of children and adolescents diagnosed with childhood obsessive compulsive disorder. Noro Psikiyatr Ars. 2014; 51: 334-43.

[30] Vivan SA, Rodrigues L, Wendt G, Bicca MG, Braga
DT,Cordioli AV. Obsessive-compulsive symptoms and obsessive-compulsive disorder in adolescents: a population-based study. Revista Brasileira de Psiquiatria. 2014; 36: 111-8.

[31] Nissen J, Powell S, Koch SV, Crowley JJ, Matthiesen M, Griceet DE, et al. Diagnostic validity of early-onset obsessive-compulsive disorder in the Danish Psychiatric Central Register: findings from a cohort sample. BMJ Open 2017; 7: e017172.

[32] Ruscio AM, Stein DJ, Chiu WT, Kessler RC. The epidemiology of obsessive-compulsive disorder in the National Comorbidity Survey Replication. Mol Psychiatry. 2010; 15: 53-63.

[33] Hwang SH, Kwon JS, Shin Y, Lee KJ, Kim YY, Kim MS. Neuropsychological profiles of patients with obsessive-compulsive disorder: early onset versus late onset. J Int Neuropsychol Soc. 2007; 13: 30-7.

[34] Torres AR, Prince MJ, Bebbington PE, Bhugra D, Brugha TS, Farrell M, et al. Obsessive-compulsive disorder: Prevalence, comorbidity, impact, and help-seeking in the British National Psychiatric Morbidity Survey of 2000. Am J Psychiatry 2006; 163: 1978-85.

[35] Jacob ML, Larson MJ, Storch EA. Insight in adults with obsessive-compulsive disorder. Compr Psychiatry. 2014; 55: 896-903.

[36] Catapano F, Perris F, Fabrazzo M, Cioffi V, Giacco D, De Santis V, et al. Obsessive-compulsive disorder with poor insight: A three-year prospective study. Prog Neuropsychopharmacol Biol Psychiatry. 2010; 34: 323-30.

[37] Bellino S, Patria L, Ziero S, Bogetto F. Clinical picture of obsessive-compulsive disorder with poor insight: A regression model. Psychiatry Res. 2005; 136: 223-31.

[38] Gothelf D, Aharonovsky O, Horesh N, Carty T, Apter A. Life events and personality factors in children and adolescents with obsessive-compulsive disorder and other anxiety disorders. Compr Psychiatry. 2004; 45: 192-8.

[39] Hettema JM, Neale MC, Kendler KS. A review and meta-analysis of the genetic epidemiology of anxiety disorders. Am J Psychiatry. 2001; 158: 1568-78.

[40] do Rosario-Campos MC, Leckman JF, Curi M, Quatrano S, Katsovitch L, Miguel EC, et al. A family study of early-onset obsessive-compulsive disorder. Am J Med Genet B Neuropsychiatr Genet. 2005; 136B: 92-7.

[41] Mueser KT, editor. Integrated Treatment for Dual Disorders: A Guide to Effective Practice. New York: Guilford Press; 2003.

[42] Mancebo MC, Grant JE, Pinto A, Eisen JL, Rasmussen SA. Substance use disorders in an obsessive compulsive disorder clinical sample. J Anxiety Disord. 2009; 23: 429-35.

[43] Practice guideline for the treatment of patients with obsessive-compulsive disorder. Arlington, Va: American Psychiatric Association; 2007.

[44] NICE. Obsessive-compulsive disorder: Core interventions in the treatment of obsessive-compulsive disorder and body dysmorphic disorder. London: NICE; 2005. 
[45] Franklin ME, Sapyta J, Freeman JB, Khanna M, Compton S, Almirall D, et al. Cognitive behavior therapy augmentation of pharmacotherapy in pediatric obsessive-compulsive disorder: the Pediatric OCD Treatment Study II (POTS II) randomized controlled trial. JAMA. 2011; 306: 1224-32.

[46] Watson HJ, Rees CS. Meta-analysis of randomized, controlled treatment trials for pediatric obsessive-compulsive disorder. J Child Psychol Psychiatry. 2008; 49: 489-98.

[47] Skoog G, Skoog I. A 40-year follow-up of patients with obsessive compulsive disorder. Arch Gen Psychiatry. 1999; 56: 121-7. 